\title{
Risk factors for psychiatric morbidity among bank workers in a northern city of Nigeria
}

A D Yussuf, FMC Psych

Department of Behavioural Sciences, University of Ilorin Teaching Hospital, Nigeria

Objective. To determine the prevalence of psychiatric morbidity in bank workers in Ilorin, Nigeria, and the sociodemographic and work-related factors that may be associated with poor psychological health.

Method. This cross-sectional two-staged study conducted between March and July 1999 involved screening using the 30-item General Health Questionnaire (GHQ-30), a sociodemographic questionnaire, the Present State Examination (PSE) schedule and diagnostic criteria from the 10th edition of the International Classification of Diseases (ICD-10).

Data source. Bank workers in the three local government areas (west, east, and south) of llorin, a city in the middle belt of Nigeria.

Data analysis. Data were analysed using Epilnfo version 6.0. Frequency distribution, cross tabulation, and chi-square analyses were obtained. The level of statistical significance was set at $5 \%$.

Result. Four hundred and thirty workers responded satisfactorily to the questionnaires (response rate 76\%); 77 respondents (18\%) were GHQ-positive and therefore had psychiatric morbidity. There was a significant association between psychiatric morbidity and age, gender, number of children, belonging to a social club, workload, promotion, and job status.

Conclusion. The implications of these findings are discussed and possible medical and administrative interventions advocated.
Various factors such as age, gender, social support, marriage, separation, promotion or demotion, poor remuneration, work pressure, family problems, unfulfilled social expectations, and job insecurity have long been identified as possible causes of psychological disturbance. Stress indicators identified among occupational groups include somatic complaints, sleep disturbances, anxiety, neurasthenia, agoraphobia, dysthymia, depression, schizophrenia, and suicide attempts. ${ }^{1.19}$

The work environment, organisational conditions, workers' capacities, job description and needs, social and work conditions, and culture may interact with workers' perceptions and experience to influence physical and psychological health. ${ }^{14}$ Psychological problems at work can manifest as poor work performance, absenteeism, excessive tobacco and alcohol consumption, poor lifestyle, poor interpersonal relations, and impaired social functions. ${ }^{14,2032}$

In Nigeria it has become increasingly difficult for the majority of people to secure sustainable employment; many employers are continually reorganising and restructuring because of the dwindling economy and unstable political environment. This has particularly affected the banking industry in Nigeria.

The prevalence of mental ill health has been estimated at between $10 \%$ and $18 \%$ in Nigeria and this is consistent with estimates from other developing countries. ${ }^{33}$ This might be due to the prevailing sociopolitical and economic problems that pervade many African countries. This view is supported by the work of German, ${ }^{34}$ who reported a rapid increase in the number of people seeking assistance for mental ill health in African countries as a result of increasing sociopolitical turmoil. In this study, we attempted to determine the rate of psychiatric morbidity in bank workers in Nigeria and to identify factors that may be associated with this morbidity. 


\section{Materials and methods}

The study was conducted among bank workers in llorin, Nigeria, between March and July 1999. The town of Ilorin was upgraded from a provincial headquarter to the state capital following the creation of Kwara State in 1967.35 The town covers about 690 $\mathrm{km}^{2}$ and comprises three local government areas (LGAs) (west, east, and south) peopled almost exclusively by the Yoruba tribe. The population totals $566000 .^{36}$ The lingua franca is Yoruba. Banking is one of the major industries in the town and there are 13 commercial banks and one branch of the Apex (Central) bank. The staff complement of these banks ranges from 20 to 200, with the highest staff complement at the Central bank. An average bank worker works a minimum of 11 hours per day (from 7h30 to 18h30), and a minimum of 6 days per week (Monday to Saturday). Thus, an average bank worker works long hours, is likely to be overworked and emotionally stressed, and is at high risk for psychiatric morbidity.

Subjects for the study were invited to participate and were required to provide written, informed consent. The majority were willing to participate because they felt that it provided an opportunity to get medical advice on work-related and personal problems, and to express opinions on non-conducive work-related conditions. Confidentiality was assured. Five hundred and sixty-three bank employees consented to participate. Previous history of psychiatric illness was an excluding factor.

The study was conducted in two stages: the first stage involved screening for psychiatric morbidity using the 30-item General Health Questionnaire (GHQ-30). ${ }^{37}$ The GHQ-30 is a screening instrument to detect current, diagnosable psychiatric disorders and is intended for use in general practice and community settings. ${ }^{37}$ The $\mathrm{GHQ}$ scoring method $(\mathrm{O}-\mathrm{O}-1-1)$ was adopted and a cut-off point of 4 was used in accordance with previous validation studies. ${ }^{38-40}$ Each questionnaire booklet was numbered serially (from 001 to 1 000), and the name/bank of every subject was written against the corresponding number on the questionnaire booklet on a 'tracer sheet'.

This facilitated contact tracing of subjects for the second stage of the study. In the second stage subjects were interviewed using the Present State Examination (PSE) schedule ${ }^{41}$ and diagnostic criteria from the 10th edition of the International Classification of Diseases (|CD-10), ${ }^{42}$ as previously used in this environment. ${ }^{15,40,43,45}$ Psychiatric diagnoses were assigned.

\section{Results}

Results of the first stage of the study are presented. The response rate was $76 \%$ (430 of 563 subjects). Seventy-seven subjects (18\%) had a score of 4 or more on the GHQ (median 5.0, range 4 - 20) and were therefore assessed to have poor psychological health.

\section{Sociodemographic characteristics and morbidity (Table I)}

\section{Age}

The majority of respondents ( $N=271,67.4 \%$ ) were between 30 and 44 years of age, with $70 \%$ of respondents with psychiatric morbidity falling into this age group. Age showed a significant

Table I. Sociodemographic characteristics of respondents (N (\%))

\begin{tabular}{|c|c|c|}
\hline $\begin{array}{l}\text { Sociodemographic } \\
\text { variables }\end{array}$ & $\begin{array}{l}\text { GHQ negative respondents } \\
\qquad(N=353)\end{array}$ & $\begin{array}{c}\text { GH positive respondents } \\
\qquad(N=77)\end{array}$ \\
\hline \multicolumn{3}{|l|}{ Age } \\
\hline Below 30 years $(N=46)$ & $34(74)$ & $12(26)^{*}$ \\
\hline 3044 years $(N=271)$ & $217(80)$ & $54(20)$ \\
\hline 45 years and above $(N=85)$ & 74 (87) & $11(13)$ \\
\hline \multicolumn{3}{|l|}{ Gender } \\
\hline Male $(N=294)$ & 231 (79) & $63(21)^{*}$ \\
\hline Female $(N=123)$ & $110(89)$ & $13(11)$ \\
\hline \multicolumn{3}{|l|}{ Number of children } \\
\hline 02 children $(N=146)$ & $111(76)$ & $35(24) \dagger$ \\
\hline Three or more children $(N=266)$ & $228(86)$ & $38(14)$ \\
\hline \multicolumn{3}{|l|}{ Social club } \\
\hline Belongs to social club $(N=224)$ & 189 (84) & $35(16)^{*}$ \\
\hline Does not belong to social club $(N=168)$ & $128(76)$ & $40(24)$ \\
\hline $\begin{array}{l}{ }^{*} p<0.01 \\
+p<0.05\end{array}$ & & \\
\hline
\end{tabular}


positive association with psychiatric morbidity $\left(x^{2}=3.65, \mathrm{df}=5\right.$, $p<0.01)$. Two hundred and ninety-four subjects (71\%) were males and $123(29 \%)$ were females. Sixty-three male respondents (21\%) had poor psychological health compared with $13(11 \%)$ female respondents $\left(x^{2}=6.86, d f=1, p<0.01\right)$.

\section{Marital and family status}

The majority of respondents were married ( $N=342,80 \%)$ and had 3 children ( $N=266,65 \%)$. Fifty-five (13\%) were single, and 20 (5\%) widowed, separated or divorced. Sixty-six married respondents (19\%) had psychiatric morbidity compared with 8 single respondents (14.5\%), and 2 (10\%) who were widowed, separated or divorced. Respondents with 2 or fewer children ( $N$ $=35,24 \%$ ) were significantly more likely to have psychiatric morbidity than respondents with 3 or more children ( $N=38,14 \%$ ) $\left(x^{2}=6.07, d f=2, p<0.0138\right)$.

\section{Educational status}

Twenty-eight respondents (7\%) had secondary education or equivalent, 292 (72\%) had higher education, and 85 (21\%) had an additional qualification. Among respondents with at least secondary education or equivalent, 2 (7\%) had psychiatric morbidity compared with 55 (19\%) of those with higher education, and 20
(24\%) of those with additional qualifications (e.g. postgraduate diploma, masters degree in business administration (MBA), Fellow of the Chartered Institute of Nigeria (ICAN)). These differences were not statistically significant.

\section{Religious and social factors}

Three hundred and six respondents (80\%) belonged to a religious group, while $77(20 \%)$ did not. Affiliation to a religious group was not significantly associated with psychiatric morbidity. Sixty $120 \%$ ) of those who belonged to a religious group had poor psychological health compared with $12(16 \%)$ who did not belong to a religious group. However, 40 (24\%) of the 168 respondents (43\%) who did not belong to a social club had psychiatric morbidity, compared with 35 (16\%) of the 224 respondents (57\%) who did belong to a social club (Yates corrected $x^{2}=3.64, \mathrm{df}=$ $1, p<0.051$. Not belonging to a social club was therefore more likely to be associated with psychiatric morbidity.

\section{Employment characteristics and morbidity (Table II)}

One hundred and eighty-two respondents (44\%) had worked 10 years or less, while 229 (56\%) had worked more than 10 years. Forty-one $(23 \%)$ of those in the former category had poor psychological health compared with 32 (14\%) in the latter category

Table II. Psychosocial factors at work of respondents (N (\%))

\begin{tabular}{|c|c|c|}
\hline Work factors & $\begin{array}{l}\text { GHQ negative respondents } \\
\qquad(N=353)\end{array}$ & $\begin{array}{l}\text { GHQ positive respondents } \\
\qquad(N=77)\end{array}$ \\
\hline \multicolumn{3}{|l|}{ Work experience } \\
\hline 10 years or less $(N=182)$ & $141(77.5)$ & $41(22.5)^{*}$ \\
\hline 10 years or more $(N=229)$ & $197(86)$ & $32(14)$ \\
\hline \multicolumn{3}{|l|}{ Work overtime } \\
\hline Works extra hours $(N=384)$ & $318(83)$ & $66(17)$ \\
\hline Does not work extra hours ( $N=22)$ & $13(59)$ & $9(41) \dagger$ \\
\hline \multicolumn{3}{|l|}{ Desirability of overtime } \\
\hline Desirable $(N=93)$ & $91(98)$ & $2(2) \ddagger$ \\
\hline Not desirable $(N=289)$ & $225(78)$ & $64(22)$ \\
\hline \multicolumn{3}{|l|}{ Competence at job } \\
\hline Above average $(N=92)$ & $74(80)$ & $18(20)^{*}$ \\
\hline Appropriate $(N=262)$ & $223(85)$ & $39(15)$ \\
\hline Below average $(N=41)$ & $28(68)$ & $13(32)$ \\
\hline \multicolumn{3}{|l|}{ Regularity of promotion } \\
\hline Last promotion $<5$ years ago $(N=297)$ & $238(80)$ & $59(20)$ \\
\hline Last promotion $>5$ years ago $(N=75)$ & 70 (93) & $5(7) \dagger$ \\
\hline Promotion coming as expected $(N=162)$ & 147 (91) & $15(9)$ \\
\hline Promotion not coming as expected $(N=214)$ & $156(73)$ & $58(27) \ddagger$ \\
\hline \multicolumn{3}{|l|}{ Job status } \\
\hline Senior level $(N=59)$ & 49 (83) & $10(17) \dagger$ \\
\hline Middle level $(N=186)$ & $161(87)$ & $25(14)$ \\
\hline Junior level $(N=160)$ & 118 (74) & $42(26)$ \\
\hline $\begin{array}{l}* p<0.05 \\
\dagger p<0.01 \\
\ddagger p<0.001\end{array}$ & & \\
\hline
\end{tabular}


(Yates corrected $x^{2}=4,5, \mathrm{df}=1, p<0.05$ ). Three hundred and fifteen respondents (77\%) claimed to have a heavy workload, 86 $(21 \%)$ reported an appropriate workload, and $6(1 \%)$ reported a light workload. Fifty per cent ( $N=3$ ) of respondents who reported a light workload had poor psychological health compared with $21 \%(N=66)$ who reported a heavy workload $\left(x^{2}=12.82\right.$, df $2, p<0.0011$. Among those who reported working overtime, $66(17 \%)$ had poor psychological health, and among those who reported not working overtime, $9(41 \%)$ had poor health (Yates corrected $x^{2}=6.28, d f=1$, Fisher's exact 2-tailed $p<0.01$ )

The majority of respondents ( $N=289,76 \%$ ) felt that working overtime was not desirable. Among respondents who felt that the extra hours were desirable, 2 (2\%) had morbidity compared with $64(22 \%)$ of respondents who felt it was not desirable (Yates corrected $\left.x^{2}=18.31, d f=1, p<0.001\right)$. Most $(N=262,66 \%)$ felt their level of competence was appropriate to their job requirement. Among those who reported a level of competence above the job requirement, 18 (20\%) had psychiatric morbidity, among those who reported an appropriate level of competence, 39 (15\%) had morbidity, while 13 (32\%) of those who reported a level of competence below their job requirement had morbidity $\left(x^{2}=7.16, d f=2, p<0.05\right)$. Two hundred and ninety-seven subjects (80\%) had been promoted within the preceding 5 years. Among those who had been promoted within the preceding 5 years, 59 (20\%) had morbidity, compared with only $5(7 \%)$ who had been promoted more than 5 years ago (Yates corrected $x^{2}=$ 6.43, $d f=1, p<0.011$. On whether or not promotion was expected, 162 (43\%) reported that promotion was expected while 214 (57\%) reported that promotion was unexpected. An unexpected promotion was more likely to be associated with morbidity $(N=58,27 \%)$ than an expected promotion $(N=15,9 \%)$ (Yates corrected $x^{2}=17.6, \mathrm{df}=1, p<0.001$ ). Fifty-nine respondents (15\%) were at the senior level, $186(46 \%)$ at the middle level, and $160(40 \%)$ at the junior level of their respective organisations. Among the respondents at senior level, 10 (17\%) had morbidity, compared with 25 (14\%) at middle level, and 42 $(26 \%)$ at junior level $\left(x^{2}=9.36, d f=2, p<0.001\right)$. One hundred and seventy $(40 \%)$ were in the employ of federal government-owned banks, $38(9 \%)$ in state-owned banks, and 220 $(51 \%)$ in privately owned banks.

\section{Discussion}

\section{Prevalence of psychiatric morbidity}

This study found an $18 \%$ rate of psychiatric morbidity in bank employees. This prevalence is lower than the $27-80 \%$ previously reported in studies of occupational groups that have used similar instruments (i.e. the $\mathrm{GHQ}$ ). 19,39,46-48 Extra-organisational factors might be responsible for these wide variations in prevalence observed across studies. For instance, the higher prevalence rates obtained in studies in Lagos ${ }^{19,39}$ might be due to the increasingly stressful conditions that usually characterise urban cities. Several social pressures ranging from problems of accommodation and the escalating cost of living, transportation problems with incessant traffic jams, lack of social security with a high incidence of armed robbery, air and noise pollution, to overcrowding could make workers in Lagos more vulnerable than those living in less urbanised towns such as llorin.

In a study of psychiatric morbidity conducted at the medical outpatient department of the University of Ilorin Teaching Hospital, ${ }^{38}$ $69 \%$ of the population sample had psychiatric morbidity. Factors thought to be contributory to psychological distress included the unstable political/economic conditions of the country and the attendant high level of 'tension' among the general populace. A similar study done at the general outpatient clinic (GOP) of the University College Hospital, Ibadan ${ }^{45}$ found a lower rate of psychiatric morbidity of $43.3 \%$ which was significantly associated with sex, age, employment status, education, and marital status.

\section{Sociodemographic factors}

This study also found significantly higher morbidity among respondents with smaller families (i.e. two or fewer children). This is surprising because intuitively one would expect higher morbidity among those with three or more children, partly because of the increased demands that go hand in hand with a larger family. Previous studies ${ }^{17,49}$ have reported more career disruption and psychiatric disorders in women who have children. However, one explanation may be that respondents with fewer children may be in the early stages of marriage. These women may have little experience in coping with both household and work demands, resulting in a greater susceptibility to psychological ill health. Having to combine care of children and family with work demands may be stressful to women especially in the event of home-work conflict. ${ }^{11}$

The finding of significantly higher morbidity among respondents in the under-30 and 30 - 44-year age categories is partially consistent with previous studies. ${ }^{50}$ Respondents in the 30 - 49 -year age group are in the middle stage of their careers, which may be in transition. This is also a time of marriage and raising children, which in themselves may be problem-laden. In the under-30 age group respondents may not have the experience to cope with stressful situations, athough intuitively one would have expected 
this group to have comparatively fewer social and family responsibilities.

The study observed significantly higher morbidity in male respondents, a finding similar to that of previous studies. ${ }^{47}$ This finding arguably suggests that male workers are more prone to developing psychiatric disorders as they are likely to be more competitive in their work disposition. Another possible explanation is the African cultural tradition of bestowing certain responsibilities or social roles on males, for example the role of headship of the family. Thus, the impact of job loss as a result of continual restructuring that characterises the banking sector in recent times, may increase vulnerability to stress disorders among male workers. It has been reported that men in developing societies may be more exposed to stresses resulting from rapid social change than are women. ${ }^{34}$ However, other studies have found higher morbidity in women than men. " This may be attributed to the dual roles of women in society, namely coping with the burden of the household while at the same time dealing with work and office schedules.

\section{Work-related factors}

In this study respondents who reported light workloads had the highest morbidity in contrast to those who reported heavy workloads. The lowest rate of morbidity was found among those who reported acceptable workloads. One would have expected the opposite to be true but it may well be that those respondents who reported heavy workloads have adapted better to work conditions, resulting in less deleterious mental health effects. The contribution of excessive work to mental disturbance has been reported elsewhere. ${ }^{39}$ Quantitative work overload has been found to be positively associated with psychological and physical health problems ${ }^{47,51,52}$ and researchers have suggested that qualitative and quantitative overload may produce different symptoms of psychological distress. ${ }^{14}$

Moreover, contrary to previous reports, significantly lower morbidity was observed among respondents who reported working overtime. The financial benefits accrued by those working overtime in the banking sector might be contributory. Low-ranking employees were observed to have the highest rate of morbidity, while the lowest rate of morbidity was observed among middleranking employees. This finding is in contrast to previous reports. It may be hypothesised that junior employees adjust more easily to various organisational challenges and have fewer concerns relating to promotion and achievement.

\section{Conclusion and recommendations}

The study examined the general rate of psychiatric morbidity in a sample of bank employees, independent of specific psychiatric diagnosis. The 18\% prevalence of psychiatric morbidity and the significant associations between psychiatric morbidity and sociodemographic lage, gender, number of children, membership of a social club), and work-related factors (job status, workload, work hours) suggests a need to mobilise efforts towards preventing or minimising the occurrence of psychological ill health in this sector. Bank employees and management staff need to be trained properly in the identification of psychosocial factors that may be detrimental to the wellbeing of workers.

The establishment of organisational-based daycare facilities may help to mitigate the higher morbidity in respondents with children, especially women. This may alleviate some of worries associated with childcare and may reduce emotional tension and psychiatric illness.

Corporate health promotion programmes (to be funded and implemented jointly by corporations, communities, local, state, and federal governments as well as non-governmental organisations) with an emphasis on educational seminars and stress management workshops, may be useful.

Modification of work intensity by adjusting work schedules, determining appropriate break and rest periods, possibly in consultation with employees, may further reduce work tension, and reduce psychiatric morbidity. Periodic social gatherings or meetings between management and employees should also be encouraged to allow adequate and prompt dissemination of information on work processes, organisational policy, and technological changes, as well as direct ventilation of employees' problems. In the researcher's view these measures may reduce the morbidity associated with 'change' within the organisation.

\section{References}

1. Paykel ES, Myers JK, Dienelt MN, et al. Life events and depression. A controlled study. Arch Gen Psychiatry 1969; 21: 753-757.

2. Paykel ES, Prusoff BA, Myers JK. Suicide attempts and recent life events. Arch Gen Psychiatry 1975; 32: 327-329.

3. Paykel ES, Tanner J. Life events, depressive relapse and maintenance treatment. Psychol Med 1976; 6: 481-485.

4. Paykel ES, Rao BM, Taylor CN. Life stress and symptom pattern in out-patient depression. Psychol Med, 1984; 14: 559-562.

5. Paykel ES, Cooper Z, Ramana R, Hayhurst H. Life events, social support and marital relationships in the outcome of severe depression. Psychol Med 1996; 26: 121-124. 
6. Jacobs SC, Prusoff BA, Paykel ES. Recent life events in schizophrenia and depression. Psychol Med 1974; 4: 444-448

7. House, JS. Occupational stress and coronary heart disease: A Review and theoretical integration. J Health Soc Behav 1974; 15: 12-15

8. Brown GW, Harris T, Copeland JR. Depression and loss. Br J Psychiatry 1977; 130: 1-5.

9. Paykel ES. Contribution of life events to causation of psychiatric illness. Psychol Med 1978; 8: $245-247$

10. Tennant $C$, Andrews $G$. The pathogenic quality of life event stress in neurotic impairment. Arch Gen Psychiatry 1978; 35: 859-862.

11. Haw MA. Women, work and stress: A review and agenda for the future. J Health Soc Behav 1982; 23: 132

12. Rees L. The development of psychosomatic medicine during the past 25 years. J Psychosom Res 1983; 27: 157-159.

13. Levi L. Stress in industry: Causes, effects and prevention. In: Occupational Safety and Health Series 1984; 51 : 1-10.

14. International Labour Organisation/World hea th Organisation Report. Psychosocial factors at work: Recognition and control. In: Occupational Safety and Health Series 1986; 56: 5-7.

15. Gureje $O$, Adewunmi A. Life events and schizophrenia in Nigerians. A controlled investigation. BrJ Psychiatry 1988; 153: 367-369.

16. Daniels O. Cultural influences and psychiatric disorders. Gower Academic Journal 1988; 212-215

17. Kaplan $\mathrm{HI}$, Sadock VA. Additional conditions that may be a focus of clinical attention. In: Comprehensive Textbook of Psychiatry. 7 h ed. Baltimore: Williams \& Wilkins, 1995: 200796

18. Ekpo M, Morakinyo O, Sijuwola OA, et al. In: Mental Health Handbook for Primary Health Care Workers. 1st ed. Nigerian Federal Ministry of Health, 1996: 7-1 1.

19. Haruna AY, Ohaeri JU, Lawal RA, et al. Comparative study of psychiatric morbidity among workers at a paint factory in Nigeria. East Afr Med J 1998; 75 (1): 4-8.

20. Conway TL, Vickers RR, Ward, HW, Rahe RH. Occupational stress and variation in cigarette, coffee, and alcohol consumption. J Health Soc Behav 1981; 22: 155-158.

21. Cooper CL. Coping wih the stress of being a woman executive. Leadership and Organisation Development Journal 1983; 4(2): 15-16

22. Fraser TM. Human stress, work and job satisfaction: A critical approach. In: Occupational Safety and Health Series 1984, 50: 13-16

23. Puri B, Tyrer P. In: Sciences Basic to Psychiatry. Singapore: Longman Singapore Publishers, 1992: 285-286

24. Catalano R, Dooley D, Novaco RW, et al. Using ECA survey data to examine he effect of job lay-offs on violent behaviour. Hospital and Community Psychiatry 1993; 44: 974-978.

25. Kawakami N, Araki S, Haratami T, Hemi T. Relations of work stress to alcohol use and drinking problems in male and female employees of a computer factory in Japan. Environ Res 1993; 62: 314-318.

26. Ezoe S, Morimoto, K. Behavioural lifestyle and mental health status of Japanese factory workers. Prev Med 1994; 23(1): 98-105.

27. Motohashi Y, Yakano T. Sleep habits and psychosomatic heal $h$ complaints of bank workers in a megacity in Japan. J Bio-Soc Sci 1996; 27: 467-470.

28. Nor h FM, Syme, SL, Feeney A, et al. Psychosocial work environment and sickness absence among British civil servants: he Whitehall II Study. Am J Public Health 1996: 86: 332-338.
29. Yang $M$, Ho CK, Fan R, Yamg MB. Job strain and drinking behaviour. Kaohsiung Journal of Medical Sciences 1996; 12: 570-576.

30. Maruyama S, Morimoto K. Effects of long working hours on life-style, stress and quality of life among intermediate Japanese managers. Scand J Work Environ Health 1996; 22: 353-357.

31. Locker D. Work stress, job satisfaction and emotional well-being among Canadian dental assistants. Community Dent Oral Epidemiol 1996; 24: 133-136.

32. Moyle P. Sickness absence as an outcome of he stress process. British Psychological Society Proceedings 1997 5: $113-116$

33. Nigerian Federal Ministry of Heal h. Mental Health Policy, 1991.

34. German AG. Menta hea th in Africa: The extent of menta hea th problems in Africa today. An update of epidemiological knowledge. BrJ Psychiatry 1987; 151: 435-438.

35. Jimoh LAK. In: Ilorin, the Journey So Far. Ilorin: Atoto Press, 1994: 332-336.

36. Kwara State Ministry of Information and Culture. Kwara State of Nigeria, 1993, Diary.

37. Goldberg DP, Rickels K, Downing R, Hesbacher P. A comparison of two psychiatric screening tests. BrJ Psychiatry 1976; 129: 61-65.

38. Oduwole $O$, Ogunyemi AO. Psychiatric morbidity in a general medical clinic in Nigeria. East Afr Med J 1984; 61: 748-752.

39. Shankar J, Famuyiwa $\bigcirc$. Stress among factory workers in a developing country. J Psychosom Res 1991; 35: 163-166.

40. Abiodun OA. A validity study of the Hospital Anxiety and Depression Scale in general hospital units and a community sample in Nigeria. BrJ Psychiatry 1994; 165: 669-673.

41. Wing JK, Cooper, JE, Sartorius N. Measurement and Classification of Psychiatric Symptoms — an Instruction Manual for the Present State Examination. Cambridge: Cambridge University Press, 1974

42. World Hea th Organization. International Classification of Diseases. $10 \mathrm{~h}$ ed. WHO, 1992 : 149-152

43. Makanjuola ROA. Recurrent unipolar manic disorder in the Yoruba Nigerian: Further evidence. BrJ Psychiatry 1985; 147: 434-437

44. Adeyemi JD, Jegede RO. Integrating psychiatry into primary care: an experimental model. Soc Psychiatry Psychiatr Epidemiol 1994; 29: $277-280$.

45. Adeyemi JD, Jegede RO. Correlates of psychiatric morbidity and case identification: A primary care study. East Afr MedJ 1999; 76: 122-126.

46. Caplan RP. Stress, anxiety, and depression in hospital consultants, general practitioners, and senior hea th service managers. BMJ 1994; 309: 1261-1269.

47. Shigemi J, Mino Y, Tsuda T, et al. The relationship between job-stress and mental heal $h$ at work. Ind Health 1997; 35 (1): 29-32.

48. Ramirez AJ, Graham J, Richards MA, Gregory WM. British hospital consultants: the effects of job stress and job satisfaction. Lancet 1996; 347: 724-726.

49. Welner A, Marten S, Wocknick E, et al. Psychiatric disorders among professional women. Arch Gen Psychiatry 1979; 36: 169-172.

50. Reddy VS, Ramananti PV. On the job stress of middle aged and elderly executives. Managerial Psychology 1990; 1-2: 16-20

51. Houstin BK, Cates DS, Kelly KE. Job stress, psychosocial strain, and physical hea h problems in women employed full-time outside the home and homemakers. Women Health 1992: 19 (1): 1-5.

52. Beena C, Poduaval PR. Gender differences in work stress of executives. Psychological Stud ies 1992; 37: 109-113. 